\title{
The Incidence and Interrelationship of Concomitant Anomalies in Congenital Scoliosis
}

\author{
Ahmet SEVENCAN ${ }^{1}$, Abdulhamit MISIR ${ }^{1}$, Hanifi UCPUNAR², Mehmet Bulent BALIOGLU³ ${ }^{3}$, Volkan GUR ${ }^{1}$, \\ Suayip $\mathrm{AKINCl}^{4}$ \\ 1Sanliurfa Training and Research Hospital, Department of Orthopaedics and Traumatology, Sanliurfa, Turkey \\ ${ }^{2}$ Erzincan University Faculty Medicine, Department of Orthopedics and Traumatology, Erzincan, Turkey \\ ${ }^{3}$ Istinye University, Department of Orthopaedics and Traumatology, Istanbul, Turkey \\ ${ }^{4}$ Baltalimani Bone and Joint Diseases Training and Research Hospital, Department of Orthopaedics and Traumatology, Istanbul, Turkey
}

Corresponding author: Hanifi UCPUNAR hanifiucpunar@yahoo.com

\section{ABSTRACT}

AIM: To report the incidence and interrelationship of concomitant anomalies in congenital scoliosis (CS) patients.

MATERIAL and METHODS: Whole-spine computed tomography and magnetic resonance imaging (MRI) examination, echocardiography, and renal ultrasonography (USG) evaluations of 231 patients with CS were reviewed. Additionally, intraspinal pathologies and structural cardiac and renal anomalies were recorded.

RESULTS: The incidence of intraspinal pathology was 53.7\%. Echocardiography was performed in 140 of 231 patients, and congenital heart disease was detected in 38 patients. Renal USG was performed in 133 of 231 patients, and a renal disease was detected in 37 patients. In 133 patients, spinal MRI, echocardiography, and renal USG were performed. In 22 of 67 (32.8\%) patients with an intraspinal anomaly, an additional cardiac anomaly was detected. In 27 of 67 (40.3\%) patients with an intraspinal anomaly, an additional renal anomaly was detected. In $47.3 \%$ of patients with a cardiac anomaly, an additional renal anomaly was detected. In 15 of 133 patients (11.2\%) intraspinal, cardiac, and renal anomalies were identified.

CONCLUSION: Surgeons should evaluate additional anomalies in CS if patients report having a congenital anomaly. Because cardiac and renal anomalies increase intra- and postoperative complication risks, a careful and comprehensive preoperative evaluation is needed.

KEYWORDS: Congenital scoliosis, Intraspinal, Cardiac, Renal, Anomaly

\section{INTRODUCTION}

$\mathrm{C}$ ongenital scoliosis (CS) is characterized by a spinal curvature secondary to congenital vertebral malforma-

tions. Deformity of the spine secondary to failure of normal vertebral development at 4-6 weeks of gestation is an accepted criterion (16). A multifactorial etiology of scoliosis is accepted $(2,10,15)$. The genetic factors associated with CS remain largely unknown (8). However, environmental factors are proven to have a strong relationship with CS $(1,8,9,14,23)$.
Maternal diabetes mellitus, hypoxia, vitamin deficiencies, and anticonvulsant medication use have been associated with CS (9). Development of the spinal cord and organs of mesodermal origin is closely related to development of the vertebral column (1). As a result, CS is often associated with anomalies of the spinal cord, cardiovascular system, and genitourinary system (12).

Previously, the incidences of intraspinal and other organ system pathologies associated with CS were reported
Ahmet SEVENCAN (D): 0000-0002-6698-0406 Abdulhamit MISIR (1D): 0000-0002-5270-1429

Hanifi UCPUNAR (1): 0000-0001-8394-0708
Mehmet Bulent BALIOGLU (10): 0000-0003-2702-5796

Volkan GUR (D): 0000-0003-4736-6555

Suayip AKINCI (D) : 0000-0002-0422-5886 
$(1,3,16,19,20,22)$. The aim of this study was to report the incidences of a larger series and to analyze the interrelationship between associated spinal cord, cardiovascular, and urogenital anomalies.

\section{MATERIAL and METHODS}

Between 2009 and 2016, a total of 231 patients with CS were diagnosed in Baltalimani Bone and Joint Diseases Training and Research Hospital. Their medical records were retrospectively reviewed. There were 137 (59\%) females and $94(41 \%)$ males. The mean age at the time of diagnosis was $12.6 \pm 7.1$ years (range: 1 month-17 years). Patients with a history of spinal trauma, tumor, infection, syndromic patients, and meningocele were excluded. Genetic consultation notes were used in the distinction between syndromic and nonsyndromic patients.

A whole-spine computed tomography scan with threedimensional reconstructions of all 231 patients was evaluated. Congenital scoliosis was classified according to vertebral malformation as failure of formation, failure of segmentation, and mixed groups (24). Magnetic resonance imaging (MRI) of the whole spine, including the brainstem, was evaluated by a neuroradiologist for spinal anomalies. Intraspinal anomalies were classified as syringomyelia, diastematomyelia, tethered cord, or intradural mass. Caudal displacement of cerebellar tonsils of more than $5 \mathrm{~mm}$ or below the level of the foramen magnum was considered as an Arnold Chiari malformation. A pediatric cardiologist examined 140 patients for cardiac anomalies by echocardiography. An experienced radiologist evaluated 133 of 231 patients for urogenital anomalies with ultrasonography (USG). In 133 patients, echocardiography and renal USG was performed. Because this is a retrospective study, we could not recruit external consultation notes and reports of imaging studies. A pediatric cardiologist and urogenital radiologist have been available at our institution since 2011.

\section{Statistical Analysis}

Mean, standard deviation, lowest and highest frequency, and ratio were used to describe the data. The chi-square test was used to evaluate the relationships between categorical variables. A $p$ value $<0.05$ was considered to indicate a statistically significant result. SPSS IBM Statistics 22 (IBM, Armonk, New York, USA) was used for all statistical analyses.

\section{RESULTS}

A total of 231 patients with CS were evaluated in this study. Failure of formation was seen in 129 patients (55.8\%). A failure of segmentation was seen in 64 patients (27.7\%). A mixed defect was seen in 38 patients (16.5\%). The sex distributions by anomaly type and a comparison of their frequencies are presented in Table I. There was no statistically significant difference between genders or CS types.

All patients underwent MRI evaluation for a potential intraspinal pathology. An intraspinal pathology was detected in 124 patients (53.7\%). The most common intraspinal anomaly among CS patients was syringomyelia followed by the tethered cord, diastematomyelia, and intradural mass (Table II). An intraspinal pathology was found in $45.7 \%$ of male patients and $59.1 \%$ of female patients. The distributions of intraspinal anomalies in male and female patients are shown in Table II. The incidence of intraspinal pathology was significantly higher in female patients $(p=0.045)$. The distribution of intraspinal anomalies was similar to that of vertebral anomalies $(p=0.14)$ (Table III).

An echocardiography was performed in 140 (60.6\%) of 231 patients. Congenital heart disease was detected on echocardiography in 38 of 140 patients (27.1\%). The most common cardiac pathologies were valve-related pathologies (mitral valve prolapse, aortic valve insufficiency, bicuspid aortic valve, aortic valve stenosis, pulmonary valve insufficiency), followed by atrial septal defect, patent foramen ovale, dextrocardia, and cardiomyopathy (Table II). Congenital heart disease was found in $32.3 \%$ of male patients and $23.1 \%$ of female patients. There was no statistically significant difference between male and females in the incidence of cardiac pathology $(p=0.225)$. According to scoliosis type, cardiac pathology was found in $29.6 \%$ of patients with failure of segmentation, $26.2 \%$ of patients with failure of formation, and $28.4 \%$ of patients with a mixed type. According to vertebral anomalies, the distribution of cardiac anomaly was similar $(p=0.92)$ (Table III).

A renal USG was performed in 133 of 231 patients. Congenital renal disease was found in 37 of $133(27.8 \%)$ patients. The most common renal pathology was ectopic kidney and horseshoe kidney, followed by renal agenesis, renal pelvic dilatation, and other urogenital diseases such as cystic kidney, hydronephrosis, and ectasia. Congenital renal disease was found in $32.2 \%$ of male patients and $24.3 \%$ of female patients

Table I: Distribution of Vertebral Anomaly Types in Female and Male Patients

\begin{tabular}{lccccccc}
\hline Anomaly type & \multicolumn{2}{c}{ Female } & \multicolumn{2}{c}{ Male } & \multicolumn{2}{c}{ Total } & p \\
\hline Segmentation & $\mathbf{n}$ & $\%$ & $\mathbf{n}$ & $\%$ & $\mathbf{n}$ & $\%$ & 0.54 \\
\hline Formation & 40 & 29.2 & 24 & 25.5 & 64 & 27.7 & 0.50 \\
\hline Mixed & 79 & 57.7 & 50 & 53.2 & 129 & 55.8 & 0.10 \\
\hline Total & 18 & 13.1 & 20 & 21.3 & 38 & 16.4 & 100 \\
\hline
\end{tabular}

${ }^{*} p$ values indicates the comparisons of the frequencies of anomaly type between the genders. 
(Table II). There was no significant difference between males and females in the incidence of renal pathology $(p=0.92)$. According to scoliosis type, urogenital pathology was found in $33.3 \%$ of patients with failure of segmentation, $25.3 \%$ of patients with failure of formation, and $30.8 \%$ patients with the mixed type. The distribution of renal anomalies was similar to that of vertebral anomalies $(p=0.68)$ (Table III). The Arnold Chiari malformation was detected in 19 of 231 patients $(8.2 \%)$. There was no statistically significant difference between gender groups $(\mathrm{p}=0.357)$.

Figure 1 shows the relationship between intraspinal, cardiac, and renal anomalies detected in patients with CS who were evaluated with CT-scan, MRI, echocardiography, and renal
USG. In 22 of 67 (32.8\%) patients with an intraspinal anomaly, an additional cardiac anomaly was detected. In 27 of 67 (40.3\%) patients with an intraspinal anomaly, an additional renal anomaly was detected. In 18 of 38 (47.3\%) patients with a cardiac anomaly, an additional renal anomaly was detected. In 15 of 133 patients (11.2\%), intraspinal, cardiac, and renal anomalies were identified.

\section{DISCUSSION}

Spinal deformity in CS is the visible part of the iceberg. Intraspinal anomalies and other organ defects are frequent (16). In our study, we evaluated the incidences and interrelationships of intraspinal, cardiac, and renal anomalies. The incidence

Table II: Distribution of Intraspinal, Cardiac, and Renal Anomaly Types in Female and Male Patients

\begin{tabular}{|c|c|c|c|c|c|}
\hline & \multicolumn{2}{|c|}{ Female $(n=137,59 \%)$} & \multicolumn{2}{|c|}{ Male $(n=94,41 \%)$} & \multirow[t]{2}{*}{$\mathbf{p}^{*}$} \\
\hline & $\mathbf{n}$ & $\%$ & $\mathbf{n}$ & $\%$ & \\
\hline Intraspinal anomalies & \multicolumn{4}{|c|}{$53.7 \%(n=124)^{\star *}$} & \\
\hline Syringomyelia & 50 & 61.7 & 34 & 79.1 & \\
\hline Tethered cord & 33 & 40.7 & 13 & 30.2 & \\
\hline Diastematomyelia & 30 & 37 & 14 & 32.6 & \\
\hline Intradural mass & 17 & 21 & 11 & 25.6 & \\
\hline Total & 81 & 59.1 & 42 & 45.7 & 0.045 \\
\hline Cardiac anomalies & \multicolumn{4}{|c|}{$27.1 \%(n=38)^{\star \star}$} & \\
\hline Valve anomalies & 12 & 15.4 & 8 & 12.9 & \\
\hline Atrial septal aneurysm & 7 & 9 & 4 & 6.5 & \\
\hline Atrial septal defect & 6 & 7.7 & 6 & 9.7 & \\
\hline Ventricular septal defect & 3 & 3.8 & 1 & 1.6 & \\
\hline Patent foramen ovale & 2 & 2.6 & 2 & 3.2 & \\
\hline Dextrocardia & 2 & 2.6 & 0 & 0 & \\
\hline Tetralogy of Fallot & 1 & 1.3 & 1 & 1.6 & \\
\hline Cardiomyopathy & 1 & 1.3 & 0 & 0 & \\
\hline Total & 34 & 23.1 & 22 & 32.3 & 0.225 \\
\hline Renal anomalies & \multicolumn{4}{|c|}{$27.8 \%(n=37)^{\star *}$} & \\
\hline Ectopic kidney & 3 & 4.1 & 7 & 11.9 & \\
\hline Horse-shoe kidney & 5 & 6.8 & 5 & 8.5 & \\
\hline Renal agenesis & 4 & 5.4 & 4 & 6.8 & \\
\hline Renal pelvic dilatation & 4 & 5.4 & 4 & 6.8 & \\
\hline Others & 4 & 5.4 & 2 & 3.4 & \\
\hline Total & 20 & 24.3 & 22 & 32.2 & 0.314 \\
\hline
\end{tabular}

${ }^{*} p$ values indicate the comparisons of the distrubution of intraspinal, cardiac, and renal anomaly frequency between the genders.

${ }^{* *}$ An intraspinal pathology was detected $53.7 \%(n=124)$ in 231 patients.

Congenital heart disease was detected $27.1 \%$ ( $n=38)$ on echocardiography in 140 patients. A congenital renal disease was found $27.8 \%(n=37)$ in 133 patients. 
Table III: Distribution of Intra-Spinal, Cardiac, and Renal anomalies according to Congenital Scoliosis Types

\begin{tabular}{|c|c|c|c|c|c|c|c|}
\hline \multirow{3}{*}{ Anomaly Type } & \multicolumn{6}{|c|}{ Congenital scoliosis type } & \multirow{3}{*}{ p value } \\
\hline & \multicolumn{2}{|c|}{ Segmentation $(n=64)$} & \multicolumn{2}{|c|}{ Formation $(n=129)$} & \multicolumn{2}{|c|}{ Mixed $(n=38)$} & \\
\hline & $\mathbf{n}$ & $\%$ & $\mathbf{n}$ & $\%$ & $\mathbf{n}$ & $\%$ & \\
\hline \multicolumn{8}{|c|}{ Intraspinal anomaly** } \\
\hline Yes & 41 & 63.5 & 65 & 50.4 & 18 & 47.4 & \multirow{2}{*}{0.139} \\
\hline No & 23 & 36.5 & 64 & 49.6 & 20 & 52.6 & \\
\hline \multicolumn{8}{|c|}{ Cardiac anomaly*** } \\
\hline Yes & 8 & 29.6 & 22 & 26.2 & 8 & 28.6 & \multirow{2}{*}{0.92} \\
\hline No & 19 & 70.4 & 62 & 73.8 & 20 & 71.4 & \\
\hline \multicolumn{8}{|c|}{ Renal anomaly ${ }^{\star * \star *}$} \\
\hline Yes & 9 & 33.3 & 20 & 25.3 & 8 & 30.8 & \multirow{2}{*}{0.68} \\
\hline No & 18 & 66.7 & 59 & 74.7 & 18 & 69.2 & \\
\hline
\end{tabular}

${ }^{*} p$ values indicates the comparisons of the frequencies of the intraspinal, cardiac, and renal anomaly between the congenital scoliosis types. n: numbers.

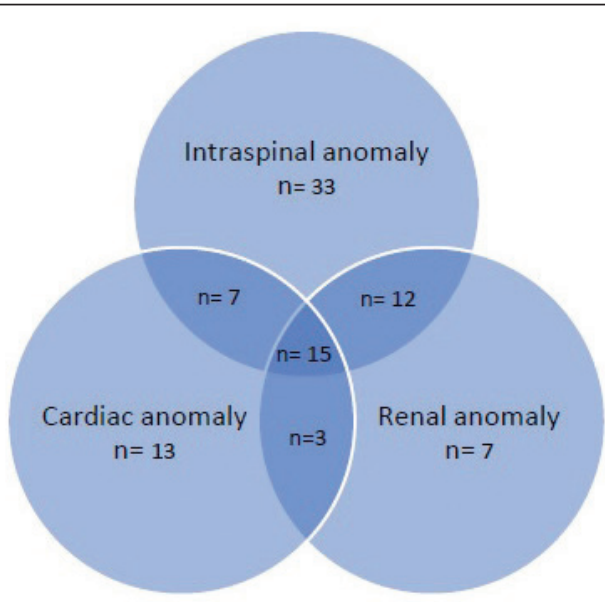

A whole-spine CT scan with three-dimensional reconstructions, MRI, echocardiography and renal USG evaluation was performed to identify potential intraspinal, cardiac, and renal anomaly in 133 of 231 patients.
Figure 1: Interrelationships of the anomalies in congenital scoliosis. A whole-spine computed tomography scan with three-dimensional reconstructions, magnetic resonance imaging, echocardiography, and renal ultrasonography evaluation was performed to identify potential intraspinal, cardiac, and renal anomaly in 133 of 231 patients. of intraspinal anomalies was found to be $53.7 \%$, which was higher than previous studies $(1,4-6,18,21)$. Syringomyelia $(67.7 \%)$ was the most common type of intraspinal anomaly in this study, which was different from the results of previous studies $(1,4-6,19,21,22)$.

The incidence of intraspinal anomaly was similar in patients with formation, segmentation, and mixed defects. Our results are in contradiction with Basu et al. (1), and Shen et al. (23). The incidence of cardiac anomalies was found to be $27.1 \%$ (38 of 140), which was in line with the study of Basu et al. (1). This incidence was higher than reported in most of the previous studies (3,5,22). Valve-related pathologies (14.3\%) (MVP being the most common) were found to be the most common type of cardiac anomaly. Liu et al. reported similar results (16).
Previously, it was suggested that thorax abnormalities might cause a change in the heart shape and, subsequently, may lead to mitral valve prolapse in idiopathic scoliosis (7). The results of our study and the study of Liu et al. (16) support this assumption in CS patients.

The incidence of cardiac anomalies was found to be similar in patients with formation, segmentation, and mixed defects. The incidence of urogenital anomalies in our study was in line with those reported in the literature, which vary from $21 \%$ to $34 \%$ $(1,4,11,13,17)$. Also, the incidence of urogenital anomalies was similar in patients with formation, segmentation, and mixed defects. According to our results, $57.9 \%$ of patients with cardiac anomaly had an additional intraspinal anomaly. This is in contradiction with Liu et al. (16), who previously reported 
rare presentation of both cardiac and intraspinal anomalies in the same patient with CS.

Our study described high incidences of additional anomalies in patients with cardiac, renal, and intraspinal anomalies. These have not been described previously. In this study, intraspinal anomalies and congenital heart disease were found to be associated with congenital renal anomalies. More than half of the patients with the Arnold Chiari malformation had an additional intraspinal anomaly. The incidence of all intraspinal, cardiac, and renal anomalies was found to be $11.2 \%$ (15 of 133 patients). This has not been described previously. High incidences of all three anomalies in the Turkish population may be associated with genetic or environmental factors. Detailed investigations on this topic are needed.

Cardiac and renal anomalies bring intra- and postoperative risks. Excessive correction in the presence of advanced thoracic deformities and cardiac pathologies may cause sudden cardiopulmonary decompensation (7). Also, intra- and postoperative metabolic disorders may develop in patients with congenital renal anomalies (22).

There are some limitations of this study. First, this is a retrospective study. Second, not all patients underwent renal and cardiac examination; therefore, bias may have occurred in the statistical analysis. The lack of genetic analysis and detailed patient histories are additional limitations.

\section{CONCLUSION}

For patients reporting a congenital anomaly, surgeons should be alert to evaluate additional anomalies in CS. Because cardiac and renal anomalies increase intra- and postoperative complication risks, a careful and comprehensive preoperative evaluation is needed.

\section{- REFERENCES}

1. Basu PS, Elsebaie $\mathrm{H}$, Noordeen $\mathrm{MH}$ : Congenital spinal deformity: A comprehensive assessment at presentation. Spine (Phila Pa 1976) 27(1):2255-2259, 2012

2. Batra S, Ahuja S: Congenital scoliosis: Management and future directions. Acta Orthop Belg 74(2):147-160, 2008

3. Beals RK, Robbins JR, Rolfe B: Anomalies associated with vertebral malformations. Spine(Phila Pa 1976) 18(10):13291332,1993

4. Bernard TN Jr, Burke SW, Johnston CE III, Roberts JM: Congenital spine deformities: A review of 47 cases. Orthopaedics 8(6):777-783, 1985

5. Bollini G, Launay F, Docquier PL, Viehweger E, Jouve JL: Congenital abnormalities associated with hemivertebrae in relation to hemivertebrae location. J Pediatr Orthop B 19(1):90-94, 2010

6. Bradford DS, Heithoff KB, Cohen M: Intraspinal abnormalities and congenital spine deformities: A radiographic and MRI study. J Paediatr Orthop 11:36-41, 1991
7. Dhuper S, Ehlers KH, Fatica NS, Myridakis DJ, Klein AA, Friedman DM, Levine DB: Incidence and risk factors for mitral valve prolapse in severe adolescent idiopathic scoliosis. Pediatr Cardiol 18(6):425-428, 1997

8. Giampietro PF: Genetic aspects of congenital and idiopathic scoliosis. Scientifica 2012:152365, 2012

9. Giampietro PF, Blank RD, Raggio CL, Merchant S, Jacobsen FS, Faciszewski T, Shukla SK, Greenlee AR, Reynolds C, Schowalter DB: Congenital and idiopathic scoliosis: Clinical and genetic aspects. Clin Med Res 1(2):125-136, 2003

10. Giampietro PF, Raggio CL, Blank RD, McCarty C, Broeckel $U$, Pickart MA: Clinical, genetic and environmental factors associated with congenital vertebral malformations. Mol Syndromology 4(1-2):94-105, 2013

11. Guerrero G, Saieh C, Dockendorf I, Diaz V: Genitourinary abnormalities in children with congenital scoliosis. Rev Chil Paediatr 60(5):281-283, 1989

12. Hedequist D, Emans J: Congenital scoliosis. A review and update. J Pediatr Orthop 27:106-116, 2007

13. Hensinger R, Lang JE, MacEwen GD: Klippel-Feil syndrome: A constellation of associated abnormalities. J Bone Joint Surg Am 56:1246-1250, 1974

14. Hensinger RN: Congenital scoliosis: Etiology and associations. Spine 34(17):1745-1750, 2009

15. Li Z, Yu X, Shen J: Environmental aspects of congenital scoliosis. Environ Sci Pollut Res Int 22(8):5751-5755, 2015

16. Liu YT, Guo LL, Tian Z, Zhu WL, Yu B, Zhang SY, Qiu GX: A retrospective study of congenital scoliosis and associated cardiac and intraspinal abnormities in a Chinese population. Eur Spine J 20(12):2111-2114, 2011

17. MacEwen GD, Winter RB, Hardy JH: Evaluation of kidney abnormalities in congenital scoliosis. J Bone Joint Surg Am 54:1451-1455, 1972

18. McMaster MJ: Occult intraspinal anomalies and congenital scoliosis. J Bone Joint Surg Am 66:588-601, 1984

19. Prahinski JR, Polly DW Jr, McHale KA, Ellenbogen RG: Occult intraspinal anomalies in congenital scoliosis. J Pediatr Orthop 20(1):59-63, 2000

20. Rai AS, Taylor TKF, Smith GHH, Cumming RG, PlunkettCole M: Congenital abnormalities of the urogenital tract in association with congenital vertebral malformations. J Bone Joint Surg Br 84(6):891-895, 2002

21. Rajasekaran S, Kamath V, Kiran R, Shetty AP: Intraspinal anomalies in scoliosis: An MRI analysis of 177 consecutive scoliosis patients. Indian J Orthop 44(1):57-63, 2010

22. Sear JW: Kidney dysfunction in the postoperative period. $\mathrm{Br} \mathrm{J}$ Anesth 95(1):20-32, 2005

23. Shen J, Wang Z, Liu J, Xue X, Qiu G: Abnormalities associated with congenital scoliosis. A retrospective study of 226 Chinese surgical cases. Spine (Phila Pa 1976) 38(10):814-818, 2013

24. Winter RB: Congenital spinal deformity. In: Lonstein JE (ed) Moe's Textbook of Scoliosis and Other Spinal Deformities, 3rd ed. Philadelphia: W.B. Saunders Co., 1995:257-294 